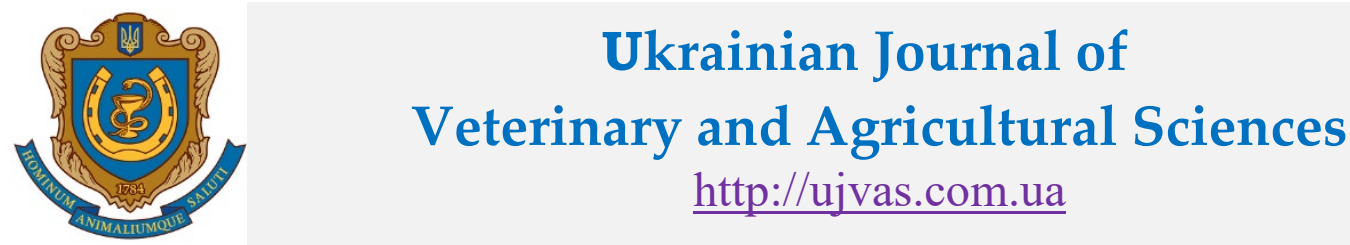

Stepan Gzhytskyi National University of Veterinary Medicine and Biotechnologies Lviv

original article $\mid$ UDC 636.598.09:616.995.132-07 $\mid$ doi: 10.32718/ujvas2-3.09

Volume 2

Number 3

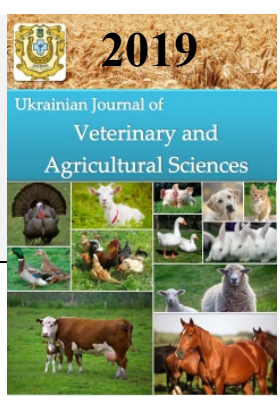

\title{
Sensitivity of life-long diagnostic methods for geese nematodes
}

\author{
O. B. Prijma \\ Stepan Gzhytskyi National University of Veterinary Medicine and Biotechnologies, Pekarska, Str., 50, Lviv, 79010, Ukraine
}

\begin{tabular}{l} 
Article info \\
Received 08.11.2019 \\
Received in revised form \\
09.12 .2019 \\
Accepted 10.12.2019 \\
\hline Correspondence author \\
Oksana Prijma \\
Tel.: +38-067-678-08-11 \\
E-mail: oks.pryima@gmail.com \\
\hline
\end{tabular}

2019 Prijma O. B. This is an openaccess article distributed under the terms of the Creative Commons Attribution License, which permits unrestricted use, distribution, and reproduction in any medium, provided the original author and source are credited.

\section{(cc) $\mathrm{Br}$}

Contents

1. Introduction ................. 39

2. Materials and methods ....... 40

3. Results and discussion ....... 40

4. Conclusions ............... 42

References .................... 42

\begin{abstract}
The basis of successful struggle and specific prevention of poultry worms is timely diagnosis, the final stage of which is the detection of the worms themselves, their eggs or larvae at various stages of development. Priority is given to the methods of lifelong laboratory diagnosis of helminthiasis, which are preferably recommended for use in all animal species, including poultry. The aim of this work was to determine the sensitivity of flotation methods of coprovoscopy for geese nematodes. Experimental determination of the efficiency of the well-known methods of flotation and their comparative evaluation of coproovoscopic diagnosis of heterocosis, capillary disease and trichostrongilosis of geese. The main indicator of the diagnostic effectiveness of the methods was the intensity of the invasion and the time spent on the flotation of the samples. The most effective methods for diagnosing geese geoccosis are Kotelnikov-Hrenov (with ammonium nitrate) - at exposures of $20 \mathrm{~min}$ and Mallory (with saturated sugar solution) - at exposures of 10-15 min. The rates of invasion intensity were respectively $62.0 \pm 4.39$ and $59.0 \pm 3.47 \mathrm{eggs} / \mathrm{g}$. In the laboratory diagnosis of goose capillary disease, the most sensitive methods were Kotelnikov-Hrenov and Mallory at exposures of 15-20 min, where infestation rates reached $34.0 \pm 2.22$ and $33.5 \pm$ $2.64 \mathrm{eggs} / \mathrm{g}$, respectively. For trichostrongilosis, the Kotelnikov-Hrenov method showed the highest sensitivity at the exposure of $20 \mathrm{~min}$, the intensity of the invasion was $32.5 \pm 3.23 \mathrm{eggs} / \mathrm{g}$. The Mallory method proved to be less effective - at an exposure of 15 min poultry invasiveness was $23.5 \pm 1.81 \mathrm{eggs} / \mathrm{g}$. The least sensitive of this invasion was the Fulleborn method (with $\mathrm{NaCl}$ ), where the intensity of the invasion gradually increased with prolonged exposure and ranged from $10.5 \pm 0.5$ to $19.5 \pm 2.45 \mathrm{eggs} / \mathrm{g}$. Based on the data obtained, it is recommended to use the most sensitive methods and to take into account the exposure, which ensures the concentration of the largest number of nematode eggs on the surface of the flotant when conducting life-long coproovoscopic diagnostics of heterosis, capillary disease and trichostrongilosis of geese.
\end{abstract}

Key words: geese, nematodes, laboratory diagnostics, efficiency, research methods.

\section{Citation:}

Prijma, O. B. (2019). Sensitivity of life-long diagnostic methods for geese nematodes. Ukrainian Journal of Veterinary and Agricultural Sciences, 2(3), 39-42.

\section{Introduction}

Domestic poultry farming has become one of the most economically attractive and competitive types of agribusiness, as evidenced by the steady dynamics of production growth, increase in domestic demand and export of products. The development of this field is constrained by many factors, including the pathogenic impact of helminths on the bird body (Poulsen et al., 2000; Ashenafi \& Eshetu, 2004).

The basis for successful control and specific prevention of bird helminthiasis is timely diagnosis, the final stage of which is the detection of the helminths themselves, their eggs or larvae at various stages of development (Hasan et al., 2018; Denizha \& Karakuş, 2019). For the purpose of life-threatening diagnosis of nematodes in poultry, coprovoscopic studies are used, namely flotation methods, the essence of which is the use of solutions with a high specific gravity, which causes the floating of nematodes eggs to the surface of the flotation fluid (Meana et al., 1998; Rehbein et al., 2011; Jacob et al., 2016).
Today, there are a large number of flotation fluids that have different diagnostic efficacy in relation to certain pathogens of helminth diseases. In addition, some known methods have certain disadvantages. Some have a destructive effect on the eggs of parasites, changing their characteristic morphological features. With the use of others, along with invasive elements, a large number of feed residues float to the surface, which also reduces their diagnostic efficiency (Nonaka et al., 1991; Mendes et al., 2005; Dahno \& Dahno, 2010).

Important in the diagnosis of helminthiasis is not only the establishment of the type of parasite, but also the determination of the intensity of invasion, which allows to detect helminths, as well as low and high degree of invasiveness of the organism. With this aim, quantitative methods of coproscopic examination are used, some of which are performed with the use of counting cameras (Pereckienè et al., 2007; Levecke et al., 2011).

Taking into account the abovementioned, there is a need to determine the sensitivity of the well-known methods of 
coproscopy for geese nematodes, which will allow to offer the most effective specialists.

The aim of this study was to determine the sensitivity of flotation methods of coprovoscopy for geese nematodes.

\section{Materials and methods}

The studies were conducted during 2019 in the laboratory of the Department of Parasitology and Ichthyopathology, Stepan Gzhytskyi National University of Veterinary Medicine and Biotechnologies Lviv.

To determine the sensitivity of well-known methods of coproovoscopic diagnostics of heterocosis, capillary disease, and trichostrongilosis, studies were conducted on sick geese belonging to the private farms in Lviv region that were disadvantaged by the invasion. The invasion intensity rate (II) was determined by quantitative method (Trach, 1992), and the number of helminth eggs per $1 \mathrm{~g}$ of litter (eggs/g). The following methods were compared: Fulleborne - with salt (Pankov, 1975); Kotelnikov-Hrenova - with ammonium nitrate (Kotelnikov, 1974); Mallory - with a saturated sugar solution (Akbaev al., 1998). Studies were performed at exposures of $10,15,20$, and $25 \mathrm{~min}$. In total, 720 coproscopic examinations were performed.

Statistical processing of experimental results was performed by determining the arithmetic mean (M), its error $(\mathrm{m})$ and the probability level $(\mathrm{P})$ using the Student's t-test table. $\mathrm{P}$ values $<0.05\left(^{*}\right)$ were considered significant

\section{Results and discussion}

The results show that the mallori method for exposures of 10 and $15 \mathrm{~min}$ (Fig. 1) proved to be the most effective method of coproovoscopic diagnostics of geese.

Thus, the average invasion intensity was $18.13 \pm 1.64$ and $59.0 \pm 3.47$ eggs/g, respectively, by $5.46-32.10 \%$
$(\mathrm{P}<0.05)$ and $22.88-70.33 \%(\mathrm{P}<0.05)$ more than using the Kotelnikov-Hrenov and Fulleborn methods. At $20 \mathrm{~min}$ exposure, the highest rates of invasion intensity (62.0 \pm $4.39 \mathrm{eggs} / \mathrm{g}$ ) were detected using the Kotelnikov-Hrenov method. Other methods were less sensitive (by 23.39$45.97 \%, \mathrm{P}<0.05)$ for geese gecosis. At the exposure of $25 \mathrm{~min}$, the rates of infestation with the use of the Kotelnikov-Hrenov and Mallory methods gradually decrease, and with the use of the Fulleborn method - increase slightly to $37.5 \pm 2.04 \mathrm{eggs} / \mathrm{g}$.

In the case of geese capillaries, the most sensitive methods of coprovascopy were Kotelnikov-Hrenov and Mallory (Fig. 2).

At $10 \mathrm{~min}$ exposure, the invasion intensity ranged from $10.76 \pm 0.76$ to $14.37 \pm 1.28 \mathrm{eggs} / \mathrm{g}$ depending on the method of study. Moreover, the highest number of eggs (by $24.64-25.12 \%, \mathrm{P}<0.05)$ was found when using methods where a saturated solution of sugar and ammonium nitrate was used as the flotation fluid. Maximum II value were detected at exposures of $15 \mathrm{~min}$ (up to $34.0 \pm 2.22$ and $33.5 \pm 2.64 \mathrm{eggs} / \mathrm{g})$ using the same methods, by 61.19 $61.76 \%(\mathrm{P}<0.05)$ is higher than when using the Fulleborn method. Subsequently, with the extension of the exposure to 20-25 min, the II decreased by using the Kotelnikov-Hrenov and Mallory methods - to $19.5 \pm 2.11$ and $16.5 \pm$ $2.08 \mathrm{eggs} / \mathrm{g}$, respectively. At the same time, in a caproscopic study of geese by the Fulleborne method, the maximum number of capillary eggs was detected at the exposure of $20 \mathrm{~min}(18.5 \pm 1.66 \mathrm{eggs} / \mathrm{g})$, but this indicator was lower by $37.28-39.34 \%(\mathrm{P}<0.05)$ than using the Kotelnikov-Hrenov and Mallory methods.

In the laboratory diagnosis of trichostrongylosis of geese, indicators of the intensity of invasion depended on the method of study and exposure (Fig. 3).

Kotelnikov-Hrenova

Mallory

Fulleborne

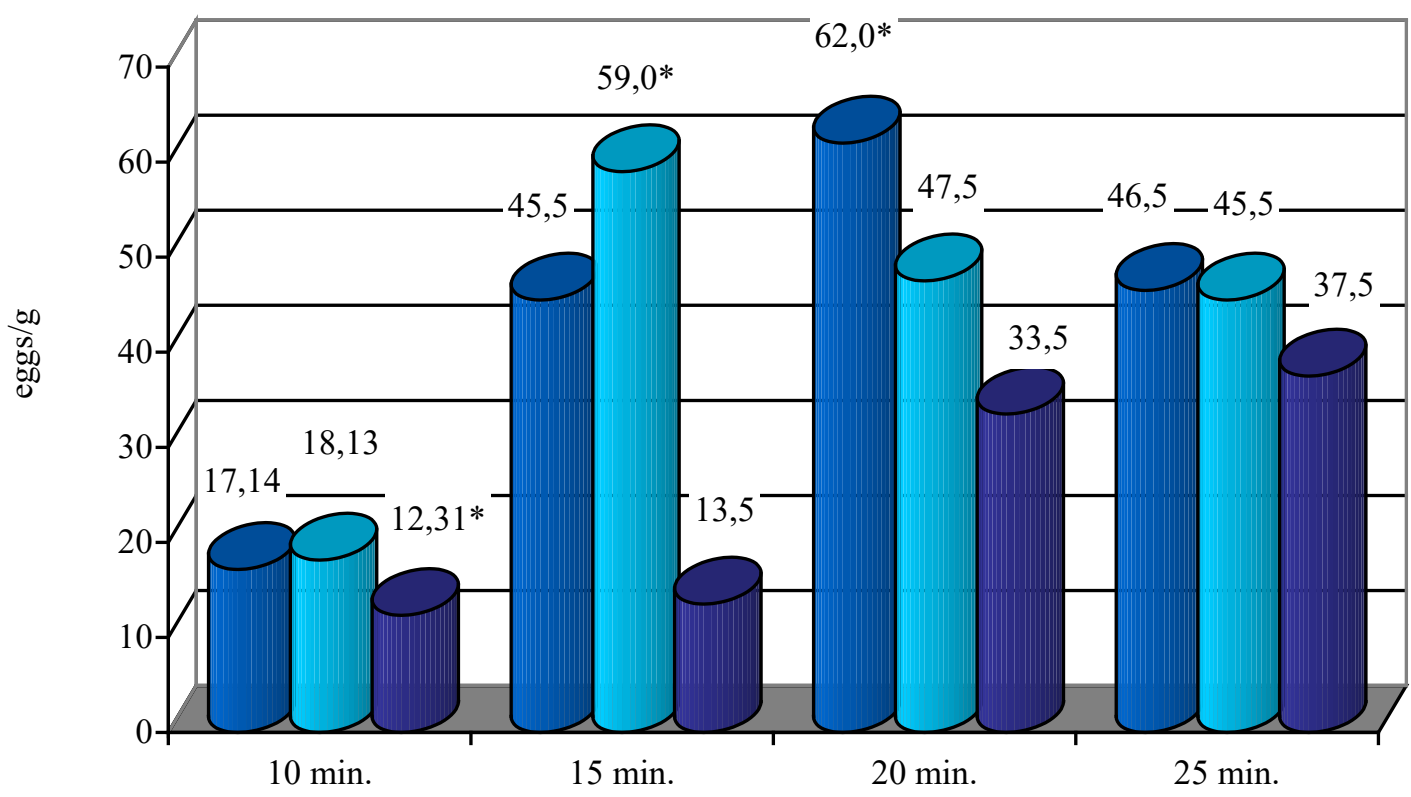

Fig. 1. Effectiveness of flotation methods for geese gecosis 

$\square$ Kotelnikov-Hrenova
$\square$ Mallory
Fulleborne

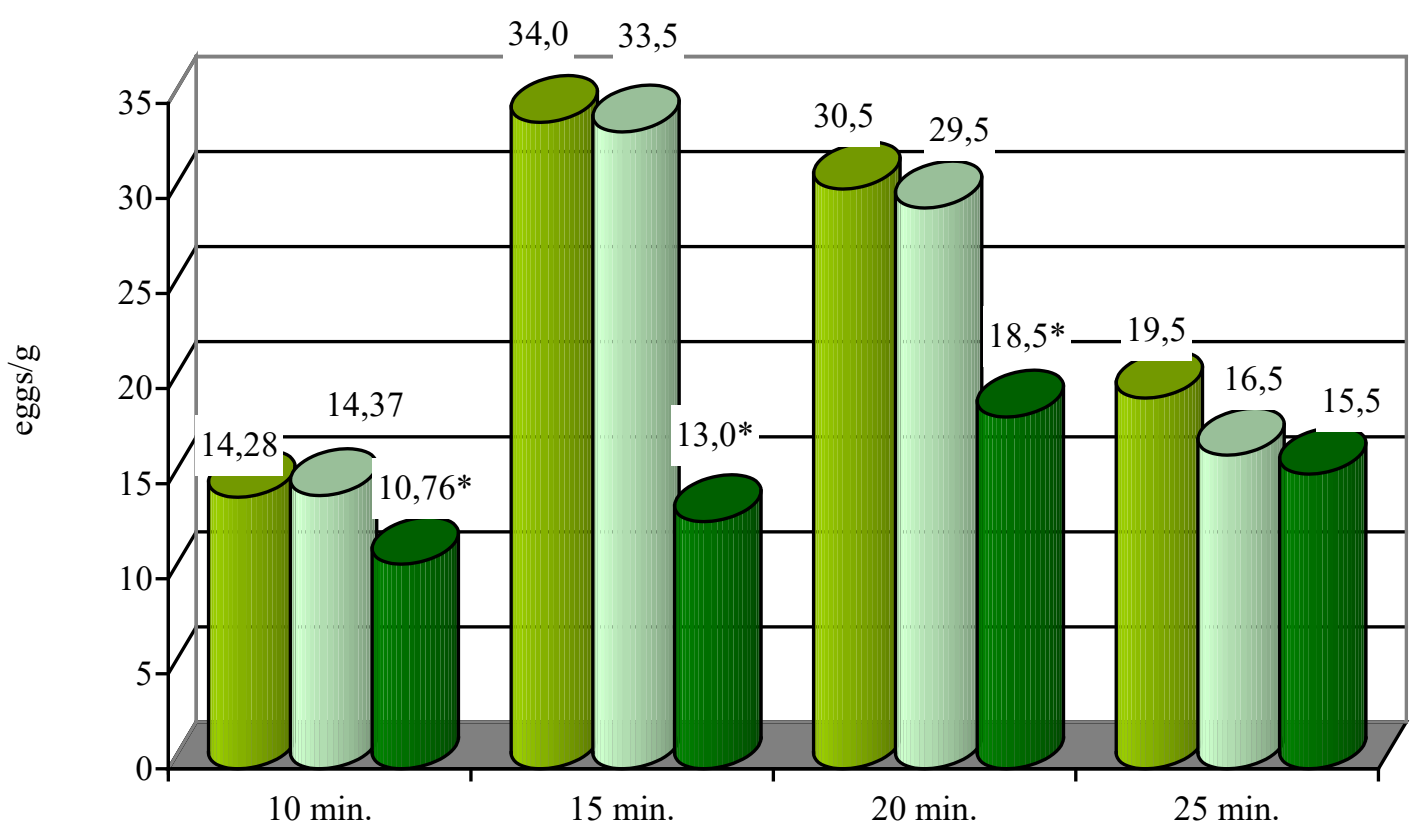

Fig. 2. Efficiency of flotation methods for geese capillary disease

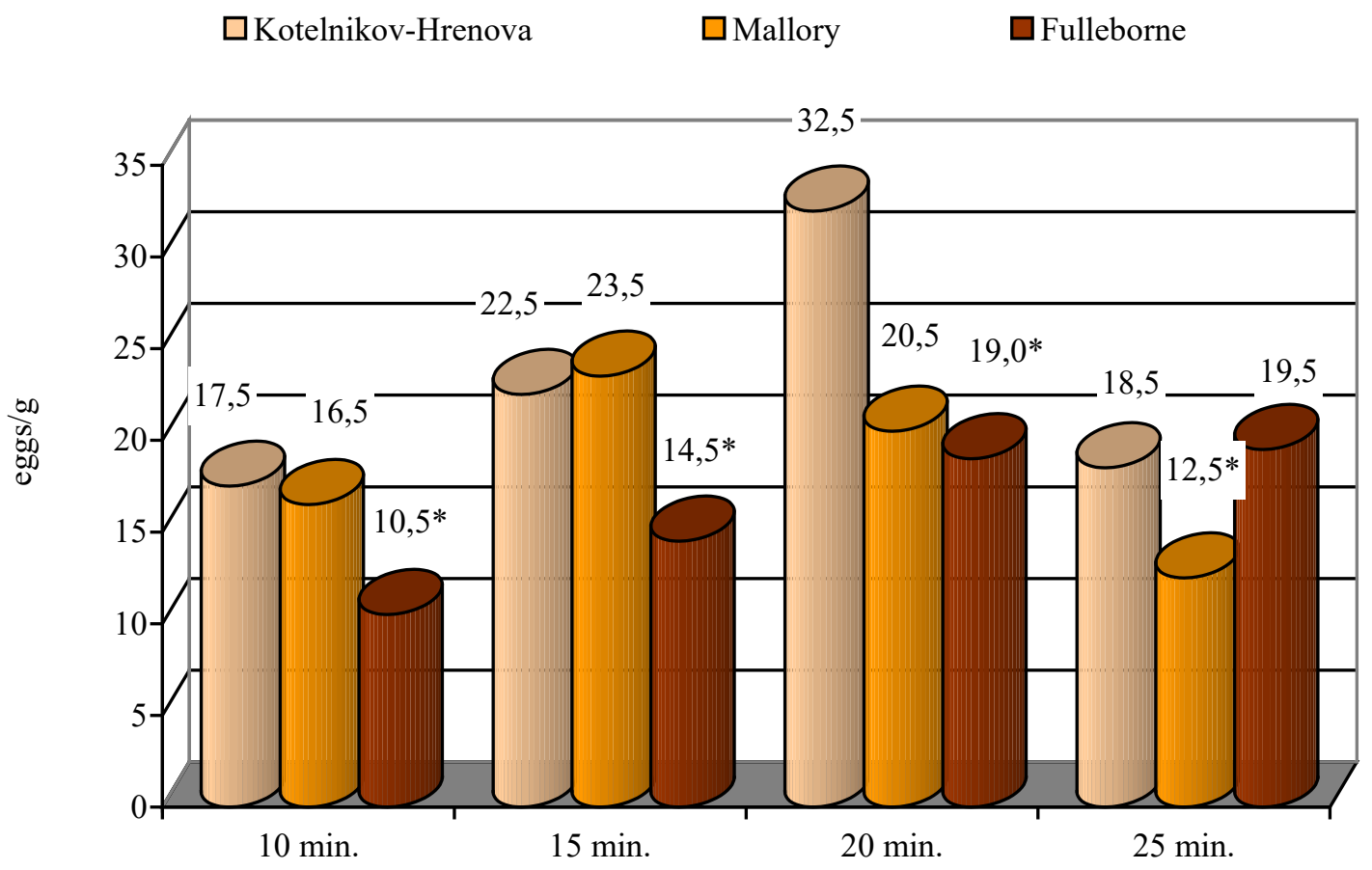

Fig. 3. Effectiveness of flotation methods for goose trichostrone

Thus, at the exposure of $10 \mathrm{~min}$, the maximum number of trichostrongilus eggs was detected using the KotelnikovHrenov and Mallory methods $(17.5 \pm 1.75$ and $16.5 \pm$ $1.66 \mathrm{eggs} / \mathrm{g})$, which is $36.36-40.0 \%$. $(\mathrm{P}<0.05)$ higher than using the Fulleborn method (10.5 \pm 0.5 eggs/g). Similar results were obtained for exposures of 15 and $20 \mathrm{~min}$. According to the Kotelnikov-Hrenov and Mallory methods, respectively, $22.5 \pm 2.16$ and $23.5 \pm 1.81 \mathrm{eggs} / \mathrm{g}$ and $32.5 \pm$ 3.23 and $20.5 \pm 1.84 \mathrm{eggs} / \mathrm{g}$, respectively, were detected. At the same time, during these exposures, the Fulleborne method showed the lowest efficiency (by 7.31-41.53\%, $\mathrm{P}<0.05)$ - the invasion intensity ranged from $14.5 \pm 1.69$ to
$19.0 \pm 2.39 \mathrm{eggs} / \mathrm{g}$. At the exposure of $25 \mathrm{~min}$ with the application of the Kotelnikov-Hrenov and Mallory methods, the intensity of the invasion gradually decreased (up to $12.5 \pm 0.99$ eggs/g), and with the application of the Fulleborne method - increase (up to $19.5 \pm 2.45 \mathrm{eggs} / \mathrm{g}$ ).

According to several researchers, coproscopy methods have different diagnostic efficacy due to the different composition and specific gravity of the flotant, the settling period for which helminth eggs should float, and the specific gravity of parasite eggs themselves (Kotelnikov, 1974; Mendes et al., 2005; Dakhno \& Dakhno, 2010). Therefore, 
well-known flotation research methods for geese nematodes were tested.

According to the results of the studies, it was found that the most sensitive methods for the diagnosis of geese gecosis are the methods of Kotelnikov-Hrenov (at 20 min exposure) and Mallory (at 10-15 min exposures). For geese capillary disease, the most sensitive methods of life diagnosis were Kotelnikov-Hrenova and Mallory at exposures of 15$20 \mathrm{~min}$. At the same time, the method of Kotelnikov-Hrenov (with exposure of $20 \mathrm{~min}$ ) showed the highest sensitivity for trichostrongilosis. It was also found that with the prolongation of exposure during the application of the KotelnikovHrenov and Mallory methods, the intensity of the invasion gradually decreased, indicating an increase in the proportion of eggs, due to their saturation with a flotant, after which they began to gradually settle. With the use of the Fulleborn method, on the contrary, with the prolongation of the exposure, the invasion intensity increased, which was due to the gradual floating of the nematode eggs on the surface of the flotant. Similar data were obtained by individual authors, who noted that with the prolongation of the settling time of the studied coprobes prepared according to flotation methods, the number of nematode eggs, oyster oocysts and isospores isolated from pigs decreased on the surface of the flotant and increased in the sediment (Yevstafieva, 2007).

\section{Conclusions}

It has been experimentally established that flotation methods of Kotelnikov-Hrenov and Mallory coproovoscopy were the most sensitive in case of geese nematodes (heteracosis, capillary disease, trichostrongilosis). In the laboratory diagnosis of heteracosis and trichostrongylosis, the most effective is the exposure of samples $20 \mathrm{~min}$ - using the Kotelnikov-Hrenov method and $15 \mathrm{~min}$ - using the Mallory method. The highest diagnostic efficacy for goose trichostrongilosis is ensured by the use of these methods at exposures of $15 \mathrm{~min}$.

\section{References}

Akbaev, M. Sh., Vodjanov, A. A., \& Kosminkov, N. E. (1998). Parazitologija i invazionnye bolezni zhivotnyh. Koloss, Moscow (in Russian).

Ashenafi, H., \& Eshetu, Y. (2004). Study on gastrointestinal helminths of local chickens in central Ethiopia. Revue de Medecine Veterinaire, 155(10), 504-507. doi: 10.1016/j.vprsr.2019.100265.

Dakhno, I. S., \& Dakhno, Yu. I. (2010). Ekolohichna helmintolohiia. Sumy (in Ukrainian).

Denizhan, V., \& Karakuş, A. (2019). The Prevalence of Gastrointestinal Helminths in Domestically Farmed Chicken in Van, Turkey. Kocatepe Veterinary Journal, 12(4), 443-447. doi: $10.30607 / \mathrm{kvj} .631622$.
Hasan, T., Mazumder, S., Hossan, M. M., Hossain, M. S., Begum, N., \& Paul, P. (2018). Prevalence of Gastrointestinal Helminth Infections in Indigenous Chickens of Selected Areas of Barisal District, Bangladesh. Bangladesh Journal of Veterinary Medicine, 16(1), 1-6. doi: 10.3329/bjvm.v16i1.37366.

Jacobs, D., Fox, M., Gibbons, L., \& Hermosilla, C. (2016). Principles of Veterinary Parasitology. Chichester, West Sussex, UK ; John Wiley \& Sons.

Kotelnikov, G. A. (1974). Diagnostics of animal helminthiasis. Koloss, Moscow (in Russian).

Levecke, B., Behnke, J. M., Ajjampur, S. S. R., Albonico, M., Ame, S. M., Charlier, J., Geiger, S. M., Hoa, N. T., Kamwa Ngassam, R. I., Kotze, A. C., McCarthy, J. S., Montresor, A., Periago, M. V., Roy, S., Tchuem Tchuenté, L. A., Thach, D. T., \& Vercruysse, J. (2011) A Comparison of the Sensitivity and Fecal Egg Counts of the McMaster Egg Counting and Kato-Katz Thick Smear Methods for Soil-Transmitted Helminths. PLOS Neglected Tropical Diseases, 5(6), e1201. doi: 10.1371/journal.pntd.0001201.

Meana, A., Luzon, M., Corchero, J., \& Gómez-Bautista, M. (1998). Reliability of coprological diagnosis of Anoplocephala perfoliata infection. Veterinary Parasitology, 74(1), 79-83. doi: 10.1016/S0304-4017(97)00145-3.

Mendes, C. R., Teixeira, A. T. L. S., Pereira, R. A. T., \& Dias, L. C. S. (2005). Estudo comparativo entre os métodos de KatoKazt e coprotest. Revista da Sociedade Brasileira de Medicina Tropical, 38(2), 178-180. doi: 10.1590/S003786822005000200010

Nonaka, N., Donoghue, A. R., Manzoni, A. M., \& Schillhorn van Veen, T. W. (1991). A survey of helminth parasites in backyard flocks in Michigan by litter examination. Avian Diseases, 35(3), 554-558. doi: 10.2307/1591219.

Pankov, N. V. (1975). Comparative evaluation of the effectiveness of helminthological methods of examinations by Fulleborn and Kato. Medical Parasitology, 44(2), 225-226 (in Russian).

Pereckienè, A., Kaziūnaitè, V., Vyšniauskas, A., Petkevičius, S., Malakauskas, A., Sarkūnas, M., \& Taylor, M. A. (2007). A comparison of modifications of the McMaster method for the enumeration of Ascaris suum eggs in pig faecal samples. Veterinary Parasitology, 149(1-2), 111-116. doi: 10.1016/j.vetpar.2007.04.014.

Poulsen, J., Permin, A., Hindsbo, O., Yelifari, L., Nansen, P., \& Bloch, P. (2000). Prevalence and distribution of gastrointestinal helminths and haemoparasites in young scavenging chickens in upper eastern region of Ghana West Africa. Preventive Veterinary Medicine, 45(3-4), 237-245. doi: 10.1016/s0167-5877(00)00125-2.

Rehbein, S., Lindner, T., Visser, M., \& Winter, R. (2011). Evaluation of a double centrifugation technique for the detection of Anoplocephala eggs in horse faeces. Journal of Helminthology, 85(4), 409-414. doi: 10.1017/S0022149X10000751.

Trach, V. N. (1992). Rekomendacii po primeneniju novogo metoda ucheta jaic gel'mintov i cist prostejshih v fekalijah zhivotnyh. Gosagroprom USSR (in Russian).

Yevstafieva, V. O. (2007). Porivnialna efektyvnist koproskopichnykh metodiv diahnostyky parazytoziv tvaryn. Visnyk Poltavskoi derzhavnoi ahrarnoi akademii, 1, 110-111 (in Ukrainian). 